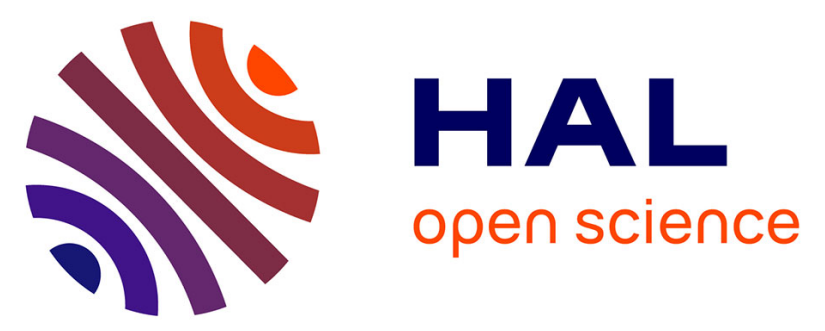

\title{
Thermomechanical analysis of polymeric foams subjected to cyclic loading: Anelasticity, self-heating and strain-induced crystallization
}

A. Lachhab, Eric Robin, Jean-Benoit Le Cam, F. Mortier, Y. Tirel, F. Canevet

\section{To cite this version:}

A. Lachhab, Eric Robin, Jean-Benoit Le Cam, F. Mortier, Y. Tirel, et al.. Thermomechanical analysis of polymeric foams subjected to cyclic loading: Anelasticity, self-heating and strain-induced crystallization. Polymer, 2017, 126, pp.19-28. 10.1016/j.polymer.2017.08.010 . hal-01580449

HAL Id: hal-01580449

https://hal-univ-rennes1.archives-ouvertes.fr/hal-01580449

Submitted on 7 May 2020

HAL is a multi-disciplinary open access archive for the deposit and dissemination of scientific research documents, whether they are published or not. The documents may come from teaching and research institutions in France or abroad, or from public or private research centers.
L'archive ouverte pluridisciplinaire HAL, est destinée au dépôt et à la diffusion de documents scientifiques de niveau recherche, publiés ou non, émanant des établissements d'enseignement et de recherche français ou étrangers, des laboratoires publics ou privés.

\section{(c)(1)}

Distributed under a Creative Commons Attribution| 4.0 International License 


\title{
Thermomechanical analysis of polymeric
}

\section{foams subjected to cyclic loading: anelasticity, self-heating and strain-induced crystallization}

\author{
A. Lachhab ${ }^{a, b, c}$ E. Robin ${ }^{a, c}$ J.-B. Le Cam ${ }^{a, c, 1}$ F. Mortier ${ }^{b, c}$ \\ Y. Tirel ${ }^{b, c}$ F. Canevet ${ }^{b, c}$ \\ ${ }^{a}$ Université de Rennes 1, Institut de Physique UMR 6251 CNRS/Université de \\ Rennes 1, Campus de Beaulieu, Bât. 10B, 35042 Rennes Cedex, France. \\ ${ }^{\mathrm{b}}$ Cooper Standard, 194 route de Lorient, 35043 Rennes - France. \\ ${ }^{\mathrm{c}}$ LC-DRIME, Joint Research Laboratory, Cooper Standard - Institut de Physique \\ UMR 6251, Campus de Beaulieu, Bât. 10B, 35042 Rennes Cedex, France.
}

\begin{abstract}
The present study investigates the thermomechanical behavior of TPU foams. Different densities were tested, including the compact state, which ensures a relevant characterization of the relative effect of the void volume fraction. A series of cyclic uniaxial tensile tests was carried out at different loading rates and different specimen densities. The effects of the density and the loading conditions on the softening, the residual strain and the hysteresis have been characterized. The thermal responses exhibit numerous particularities. First, a threshold effect in terms of the density on the self-heating has been highlighted. Second, entropic effects are weighted by energetic effects (internal energy variations) during the deformation. Typical changes in the thermal response highlight that strain-induced crystallization (SIC) and crystallite melting occur during the deformation. The characteristic stretches of this
\end{abstract}


phenomenon evolve with the maximum stretch applied, which increases the residual stretch, and the number of cycles, which induces the softening. Decreasing the density decreases the crystallinity: the volume of crystallizing matter is lower and cell wholes become more and more thin, which decreases the mobility of the molecular chains. These effects cannot be predicted from the mechanical responses and the present study provides therefore information of importance to better understand and model the effects of the density and the loading conditions on the thermomechanical behavior of TPU foams.

Key words:

polymeric foam, self-heating, strain-induced crystallization, anelasticity, infrared thermography

\section{Introduction}

The thermoplastic polyurethane elastomers (TPUs) are widely used in many applications due to their structural versability, chemical resistance, biocompatibility and high elasticity. Such polymers feature the mechanical behavior of rubber and is therefore subjected to many phenomena such as mechanical hysteresis, residual strain and softening [1]. These phenomena strongly depend on the material formulation. When foamed, TPUs exhibit high energy absorption capacity and deformability, which explains why they are extensively used for anti-vibration and shock applications, for instance in automotive, energy and military areas. In the literature, several studies have been reported on the mechanical properties of TPUs $[2,3,4,5,6]$ and TPU foams $[7,8,9,10,11,12]$. Nevertheless, material formulations and elaboration processes are different and

$\overline{1}$ Corresponding author jean-benoit.lecam@univ-rennes1.fr Fax : (+33) 223236111 
no study provides mechanical properties of both the compact and the foam states of the same TPU. Furthermore, the part of the energy dissipation due to viscosity leads to self-heating that has to be taken into account for TPU part design. As viscosity depends on the void volume fraction, a tread-off between energy absorption capacity, density and self-heating has therefore to be found.

The objective of the present study is to investigate experimentally both the mechanical and the thermal responses of stretched polymeric foams in order to highlight possible threshold effects of material density and loading conditions on the self-heating. Furthermore, such type of TPU is crystallizing under strain. As crystallization is highly exothermal, its effect on the thermal response has to be discussed as well.

The paper is organized as follows. Section 2 presents the technique used to elaborate the specimens, the loading conditions and the thermal measurement during the mechanical tests. Section 3 gives the results and compares the TPUs with different densities according to their mechanical and thermal responses. Self-heating and SIC are more particularly addressed. Concluding remarks close the paper. 


\section{Materials and experimental setup}

\subsection{Elaboration of the compact and foamed thermoplastic polyurethane elas-} tomers

The material considered here is a compact TPU referred to as Irogran $\AA$ A87H4615 TPU and was received in the form of pellets from the Huntsman corporation (The Woodlands, Texas, USA). It is elaborated by reacting together a diisocyanate, a macro diol (long chain diol), which is a polyester in the present case, and a small molecule chain-extender (butane diol) [13]. This TPU has a melting temperature of $180^{\circ} \mathrm{C}$, a density equal to $1.20 \mathrm{~kg} / \mathrm{dm}^{3}$, and a hardness of 85 Shore $\mathrm{A}$ at $23^{\circ} \mathrm{C}$. Its mechanical properties are given in Table 1. Such material is regarded as a linear block copolymer. The macroTable 1

Mechanical properties of Irogran® A87H4615 TPU

\begin{tabular}{cc} 
Properties & Values \\
\hline Hardness [Shore A] & 85 \\
Tear strength $[\mathrm{N} / \mathrm{mm}]$ & 80 \\
Tensile strength $[\mathrm{MPa}]$ & 47 \\
Stretch at failure [-] & 7.4 \\
Compression set $\left(70\right.$ hours at $\left.23^{\circ} \mathrm{C}\right)[\%]$ & 25 \\
\hline
\end{tabular}

diols correspond to the soft segments (SS) and are of the highest molecular mobility. The hard segments (HS) are built from alterning diisocyanate-chain extender sequences [19]. They are either at the glassy or the crystalline state. 
In most studies, cells are generated by using water as a chemical swelling agent. In the present study, a different process was used. It consists in mixing TPU with carbon dioxide in its supercritical state during injection, in order to significantly decrease its density.

The forming process is based on two US patents $[14,15]$ and is referred to as the Mucell process. It is described in Figure 1. In this process, a supercritical fluid (SCF, carbon dioxide in the present study) is introduced in the melt polymer located in the barrel of the injection molding. The TPU-CSF mixing is then injected in the mold, where the carbon dioxide gas expands, which leads to the cellular structure. The different densities are achieved by controlling two parameters: the SCF amount and the volume of injected matter. Further information on the solubility and interfacial tension of TPU melt in supercritical carbon dioxide and nitrogen A is provided in reference [13].

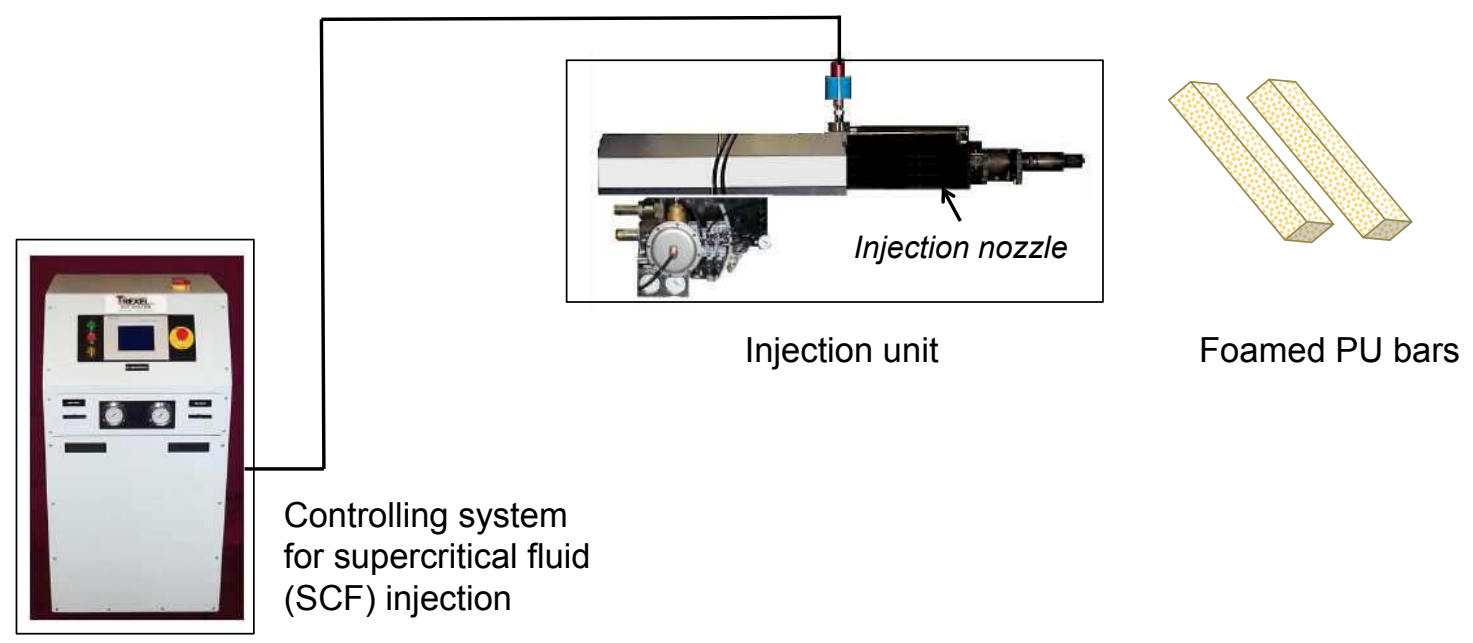

Fig. 1. Foaming procedure 


\section{ACCEPTED MANUSCRIPT}

The specimens were obtained by cutting a bar with a water jet cutting device. In order to investigate the effects of the density on the thermomechanical response, specimens with different densities were elaborated: 1.2, 0.7 and 0.5 $\mathrm{kg} / \mathrm{dm}^{3}$. They are denoted respectively $d_{1.2}, d_{0.7}$ and $d_{0.5}$ in the following. These densities are given with accuracy in the range of \pm 0.05 . It should be noted that the density equal to 1.2 corresponds to the compact state. The
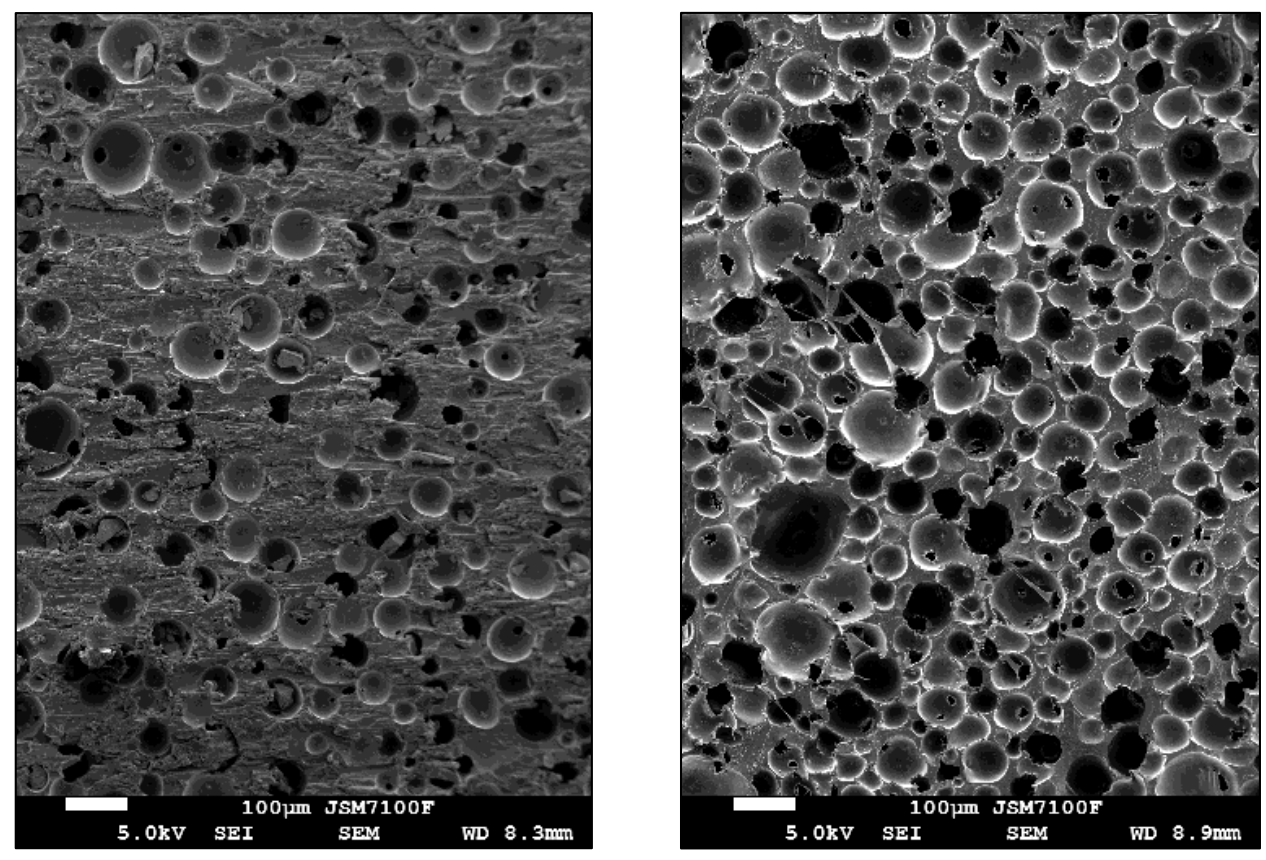

Fig. 2. SEM micrographs of the foams: $d_{0.7}$ on the left hand side, $d_{0.5}$ on the right hand side

morphology of the two foam densities has been studied using Scanning Electron Microscopy (SEM). Figure 2 gives typical micrographs obtained. In both cases, cells are spherical. Their distribution is quite regular. Their size has 
been determined from the largest circles observed on the 2D surface (135 $\mu \mathrm{m}$ in diameter for $d_{0.7}$ and $150 \mu \mathrm{m}$ for $d_{0.5}$, which is consistent with the density ratio). Cells are almost all closed for $d_{0.7}$. More connections between cells are
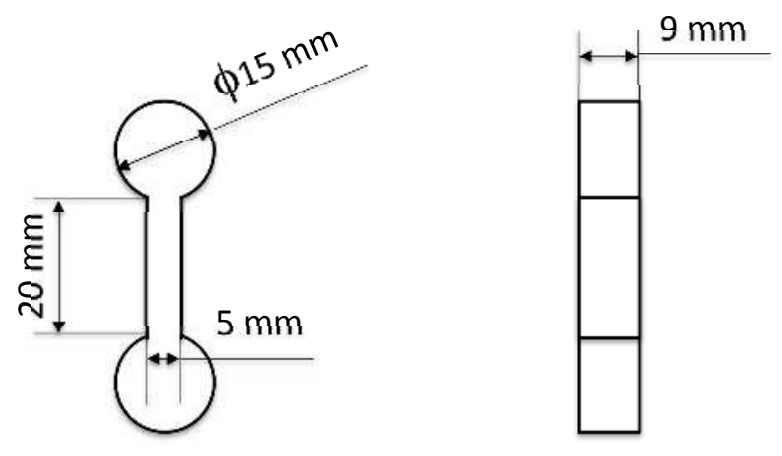

Fig. 3. Specimen geometry

The specimen geometry is presented in Figure 3. The gauge section is 20 $\mathrm{mm}$ long, $9 \mathrm{~mm}$ wide and $5 \mathrm{~mm}$ thick. It can be noted that this geometry prevents the specimen from any sliding in the grips. Moreover, the skin formed during the molding of the bar was removed from the specimen by using water jet cutting. This skin does not contain any cells and is therefore stiffer than the rest of the specimen. Consequently, it could influence significantly the mechanical and thermomechanical responses of the foamed specimen.

\subsection{Loading conditions}

Strain controlled uniaxial tensile loadings were applied using a 5543 Instron testing machine. Figure 4 presents an overview of the experimental setup. 
Mechanical tests were performed by applying five mechanical cycles at four increasing maximum stretch levels $\left(\lambda_{1}=1.5, \lambda_{2}=2, \lambda_{3}=2.5, \lambda_{4}=3\right)$ at two loading rates $( \pm 100$ and $\pm 300 \mathrm{~mm} / \mathrm{min})$. The stretch is defined as the ratio between current and initial lengths. The signal shape chosen was triangular to ensure a constant loading rate during loading and unloading. Many studies have been performed under such type of mechanical loadings [5, 16, 17, 18]. In the present study, it should be noted that the sample returns to zero strain, but a strong buckling occurs and the nominal stress becomes negative. The material is not under tension anymore. Thus, the negative nominal stress is due to the material response and the sample response that is submitted to buckling. This is why the response of the material for negative stress is not given.

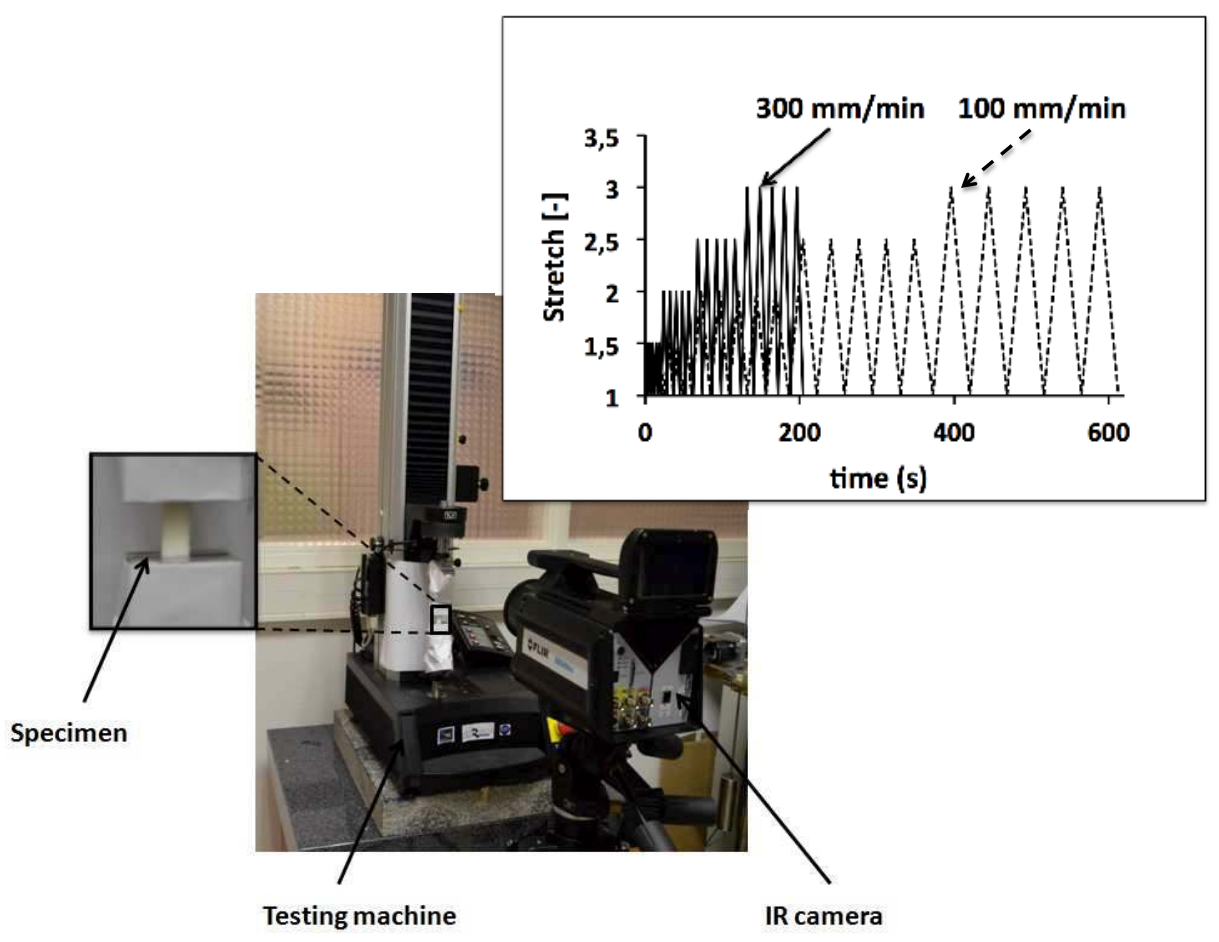

Fig. 4. Overview of the experimental setup and mechanical loadings applied 


\section{3 thermal measurement}

Temperature field measurements were performed using a FLIR X6540sc InSb infrared camera, which features a local plane array of $640 \times 512$ pixels and detectors with a wavelength range of 1.5-5.1 $\mu \mathrm{m}$ and a pitch of $15 \mu \mathrm{m}$. Integration time was equal to $1000 \mu \mathrm{s}$. The acquisition frequency was set at $50 \mathrm{~Hz}$. The thermal resolution, namely the noise-equivalent temperature difference, was equal to $20 \mathrm{mK}$ at $25^{\circ} \mathrm{C}$. The calibration of the camera detectors was performed with a black body using a Non-Uniformity Correction (NUC) procedure. The thermal quantity considered in the present study was the mean temperature variation of a small zone of $5 \times 5$ pixels at the centre of the specimen. This quantity was obtained by subtracting the initial temperature from the current one, after applying a suitable movement compensation technique to track this small zone during the test (see [20] or [21] for further information on this technique).

\section{Results and discussion}

In this section, the mechanical response of the TPUs is first presented. Then, the thermal response is given and discussed, especially the self-heating. A particular attention is finally paid on characteristic phenomena detected in the thermal response, namely the thermoelastic inversion and the strain-induced crystallization. 


\subsection{Mechanical response}

The mechanical responses obtained at $\pm 100 \mathrm{~mm} / \mathrm{min}$ and $\pm 300 \mathrm{~mm} / \mathrm{min}$ are presented for specimens $d_{1.2}, d_{0.7}$ and $d_{0.5}$ in Figures 5(a), 5(b) and 5(c), respectively. These figures give the nominal stress, defined as the force per initial surface ratio, in relation to the stretch. First, the mechanical response is non-linear. The lower the density, the lower the global stiffness: decreasing the density leads to stress-stretch curves below those obtained for higher densities. The loading rate does not affect significantly the stiffness.

For each loading condition and density, typical effects classically observed in filled elastomers are obtained: softening, residual strain and hysteresis. These effects are due to the segmented microstructure of TPU [22] and have been widely studied in the literature (see for instance [2], [3] and [4]). Nevertheless, the comparison between compact and foam states of the same TPU has never been reported in the literature, which drastically limits the investigation of the relative effects of the void volume fraction in a given TPU formulation. In the next paragraphs, the effects of the density and the loading conditions on softening, residual strain and hysteresis are more precisely detailed.

\subsubsection{Softening}

Softening is classically observed in filled rubber and is referred to as the Mullins effect. The reader can refer to [23] and [1] for further information. It is often considered as a damage phenomenon in modeling approaches [24, 25, 26, 27]. A physical interpretation of this effect in carbon black filled styrene butadiene rubber is provided in a recent study by Diaz et al [28]. Several studies 


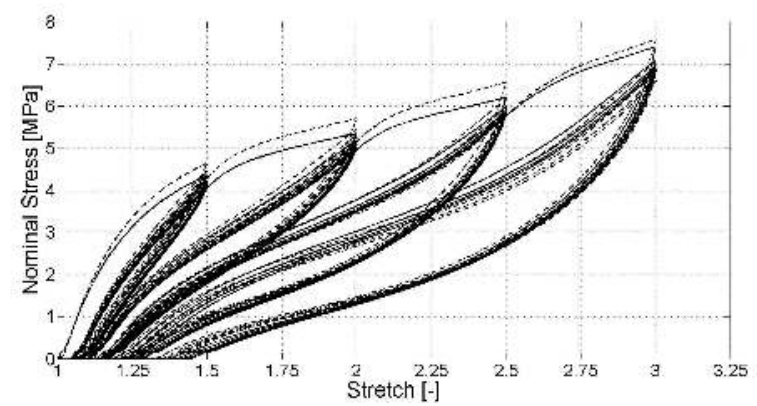

(a)

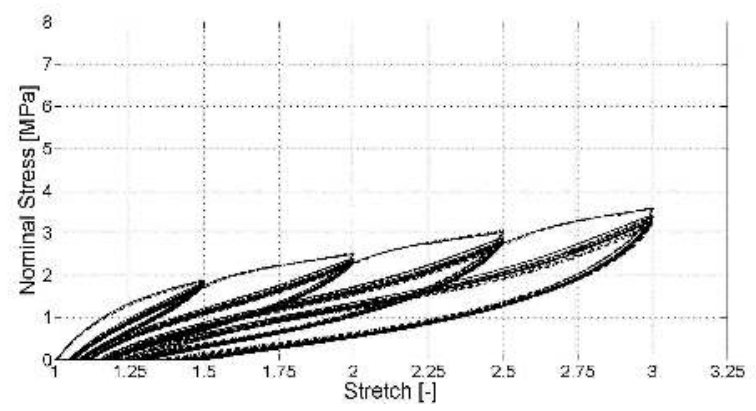

(b)

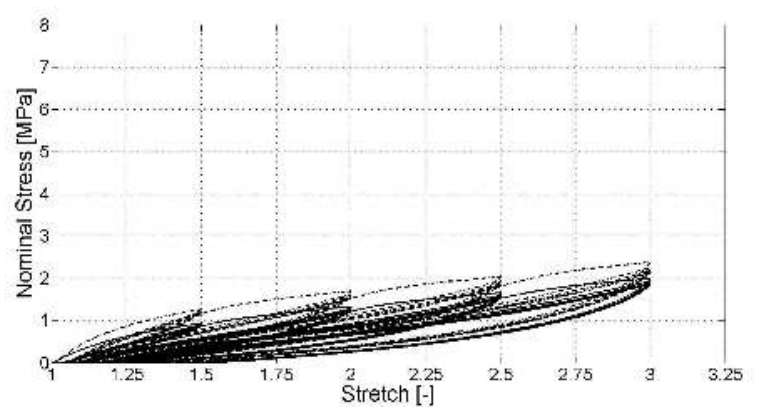

(c)

Fig. 5. Mechanical response (stress vs stretch) for the two loading rates ( \pm 100 $\mathrm{mm} / \mathrm{min}$ in solid line, $\pm 300 \mathrm{~mm} / \mathrm{min}$ in dotted line) (a) $d_{1.2}$ (b) $d_{0.7}$ (c) $d_{0.5}$.

have evidenced that similar softening effects occur in TPU $[5,6]$, while their chemistry is different from the rubbers'one. Mechanisms involved in softening are therefore not exactly the same. Several methods can be used to evaluate the softening. In the study by Machado et al[34], the amount of softening has been calculated as the ratio between the mechanical energies brought during second $\left(W_{2 L}\right)$ and first $\left(W_{1 L}\right)$ loadings $\frac{W_{2 L}}{W_{1 L}}$. These energies correspond to the 
area under the loading curves, defined as :

$$
W_{i L}=\int_{1}^{\lambda \max } \pi d \lambda, i=1,2
$$

where $\pi$ is the component of the nominal stress tensor in the loading direction.

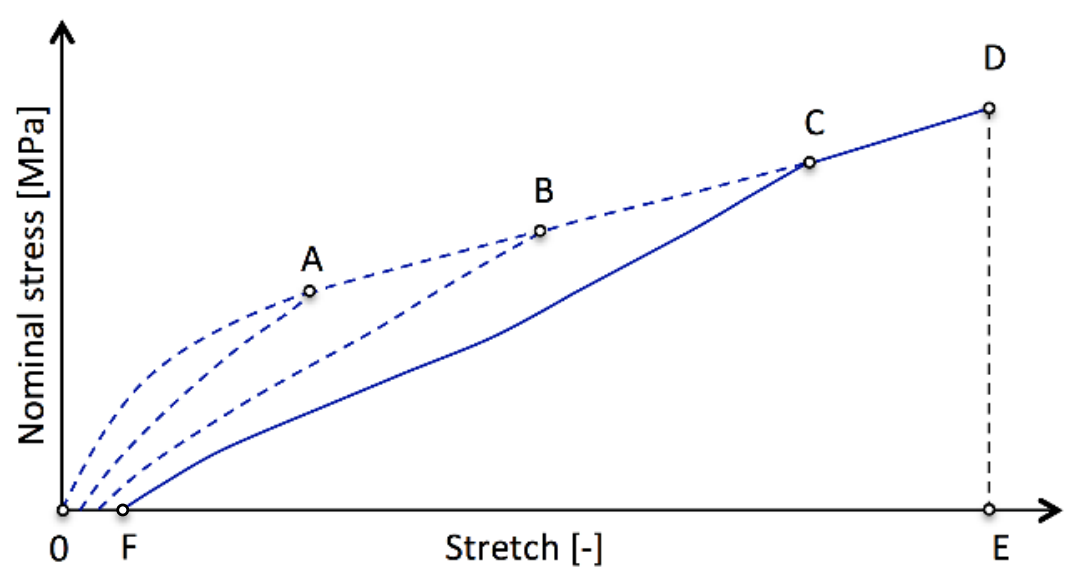

Fig. 6. Methodology to determine $W_{1 L}^{\star}$

According to the authors, such methodology enables us to remove the effect of the hysteresis from the calculation. Nevertheless, this ratio is affected by the previous mechanical cycles carried out at lower maximum stretches if any. More recently, Loo et al have proposed a new calculation for this ratio that does not account for the loading history [35]. The aim of the calculation is to determine the strain energy density $\left(W_{1 L}^{\star}\right.$ instead of $\left.W_{1 L}\right)$ that would be obtained without the effects of previous cycles at lower maximum stretches. For instance in Figure 5, the ratio is calculated for the last set of maximum stretch applied. $W_{1 L}$ is given by area FCDE while $W_{1 L}^{\star}$ is given by area OABCDE. This approach considered that curve OD is close to the curve obtained for 
a first loading of the virgin material until failure. Curve OD is therefore the equivalent monotonous loading curve.

Figure 7 presents the evolution of this ratio for different maximum stretches, for different densities and for a loading rate equal to $\pm 100 \mathrm{~mm} / \mathrm{min}$. This figure highlights that the softening increases with the stretch (the ratio decreases). Nevertheless, it depends on neither the density nor the loading rate.

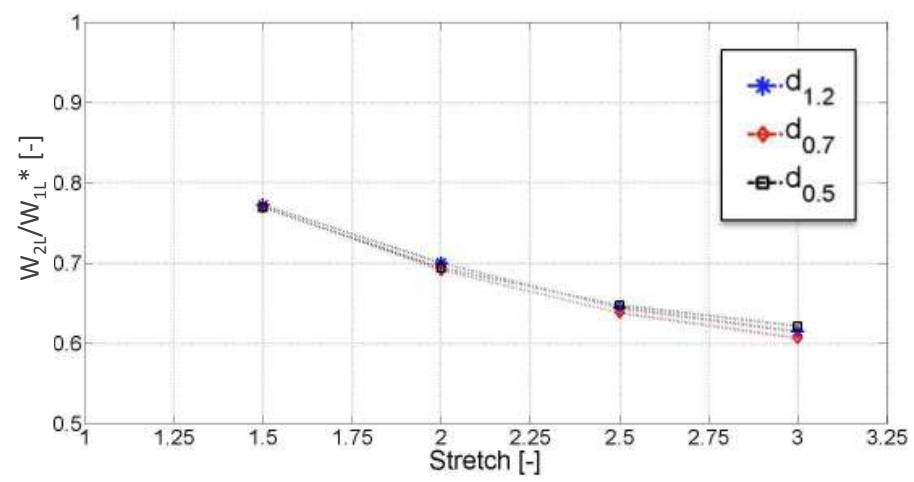

(a)

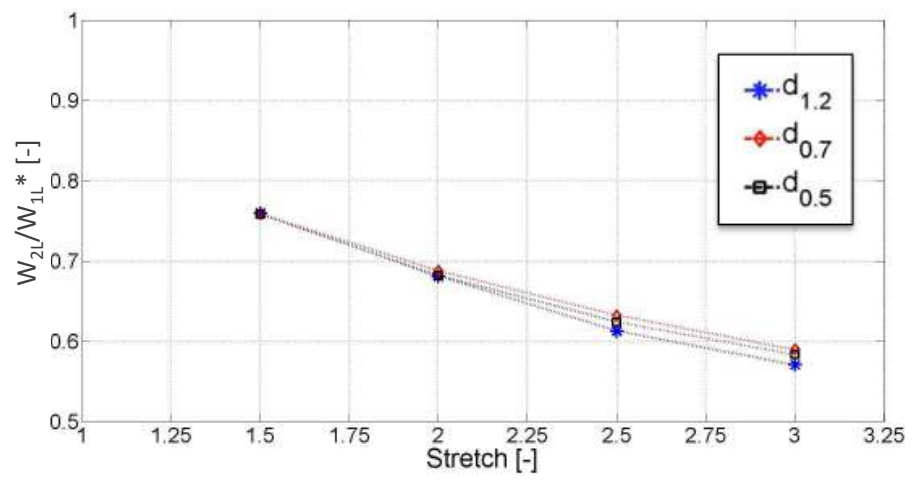

(b)

Fig. 7. Influence of the loading rate and the density effects on softening (a) \pm 100 $\mathrm{mm} / \min (\mathrm{b}) \pm 300 \mathrm{~mm} / \mathrm{min}$ 


\subsubsection{Residual strain}

Figure 8 depicts the effects of density and maximum stretch applied on the residual strain. The residual strain is defined as the strain value when the stress returns to zero at the end of the unloading. The five diagrams present the results obtained for each number of cycles in each set of maximum stretches applied. For instance, the diagram entitled " $1{ }^{\text {st }}$ cycles" gives the residual strain obtained for the first cycles of each set of maximum stretch applied.

As expected, the diagrams show that the higher the maximum stretch applied, the higher the residual strain. The maximum value of residual strain is obtained for the last cycle: the residual strain increases with the stretch and the number of cycles at a given maximum stretch. It reaches more than $40 \%$ for the lowest density and the last cycle at $\lambda_{4}=3$. Moreover, the higher the density, the lower the residual strain at a given stretch. The difference is all the more large that the maximum stretch reached is high. For the compact state (specimen $d_{1.2}$ ), the residual strain is stabilized from the third cycle at a given maximum stretch (the effect is illustrated using the dotted line curve). This stabilization is not observed in TPU foams. Concerning the effects of the loading rate, Figure 8(b) shows that the residual strain decreases if the loading rate increases. Considering Fig. 7(a) and 7(b), it clearly appears that the softening does not depend on the loading rate, i.e. it is not affected by viscous effects, as the curves obtained for the two loading rates would be quasi-superimposed. The residual strain depends therefore more on the viscosity than the softening. 


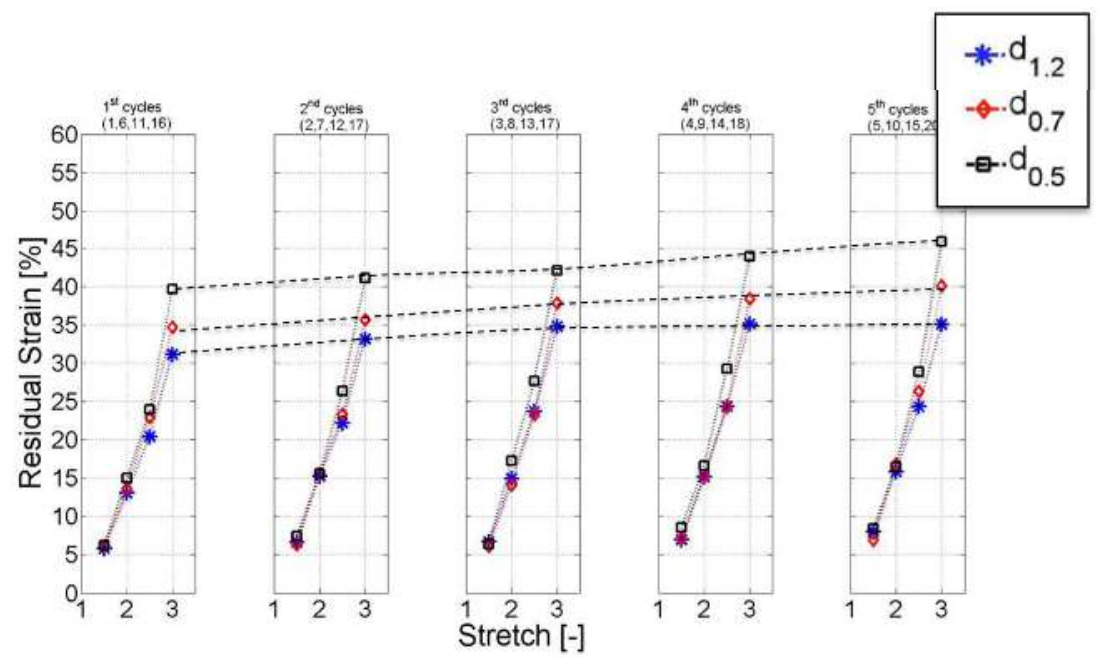

(a)
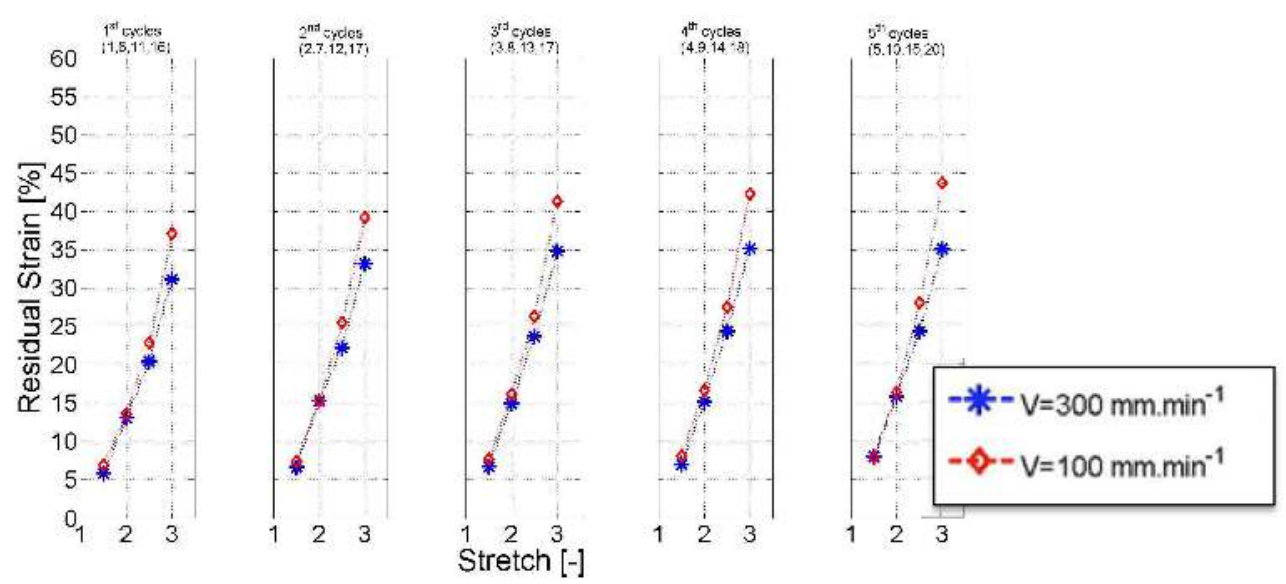

(b)

Fig. 8. Residual strain at $\pm 300 \mathrm{~mm} / \mathrm{min}$ (a) influence of the density (b) influence of loading rate for $d_{1.2}$

\subsubsection{Hysteresis}

Similarly to the previous anelastic effect, hysteresis was studied for each density and loading condition. Figure 9 gives the evolution of the stabilized hysteresis area obtained at the $5^{\text {th }}$ cycles for the three densities tested and the two loading rates applied $\pm 100 \mathrm{~mm} / \mathrm{min}$. Conclusions are the same at 
$\pm 300 \mathrm{~mm} / \mathrm{min}$.

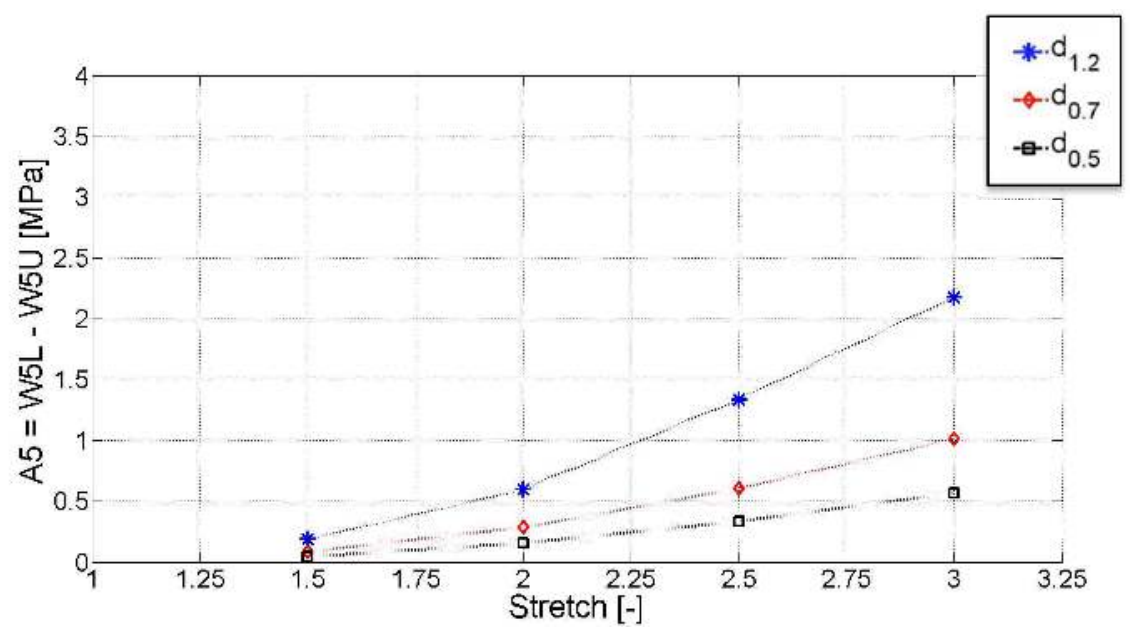

Fig. 9. Influence of the density on hysteresis at $\pm 100 \mathrm{~mm} / \mathrm{min}$

Once the material is accommodated, i.e. once the stress-stretch curve is stabilized, no more softening takes place in the mechanical response. The area of the hysteresis loop does therefore not depend on softening effect. It is clearly observed that the higher the stretch level, the higher the stabilized hysteresis area. As logically observed for viscous materials, increasing the loading rate decreases the hysteresis loop. The higher the density, the higher the hysteresis loop.

To sum up, we have shown that decreasing the density decreases the hysteresis area, slightly increase the residual strain and does not affect the stress softening. Concerning the loading rate, no significant influence was found on stress softening, while it influences significantly the residual strain and the hysteresis area. 


\subsection{Thermal response}

Temperature measurements have been performed during each mechanical test. Results obtained are presented in Figures 10(a) and 10(b) for the three densities tested at $\pm 100 \mathrm{~mm} / \mathrm{min}$ and $\pm 300 \mathrm{~mm} / \mathrm{min}$, respectively.

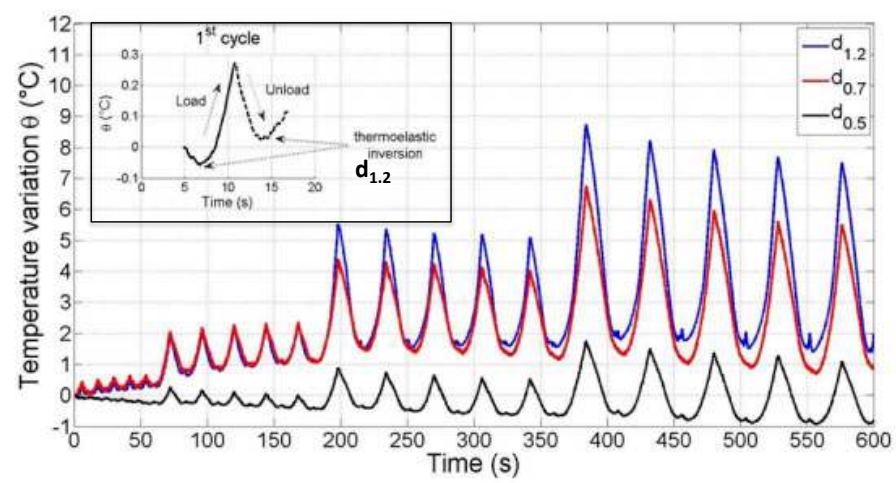

(a)

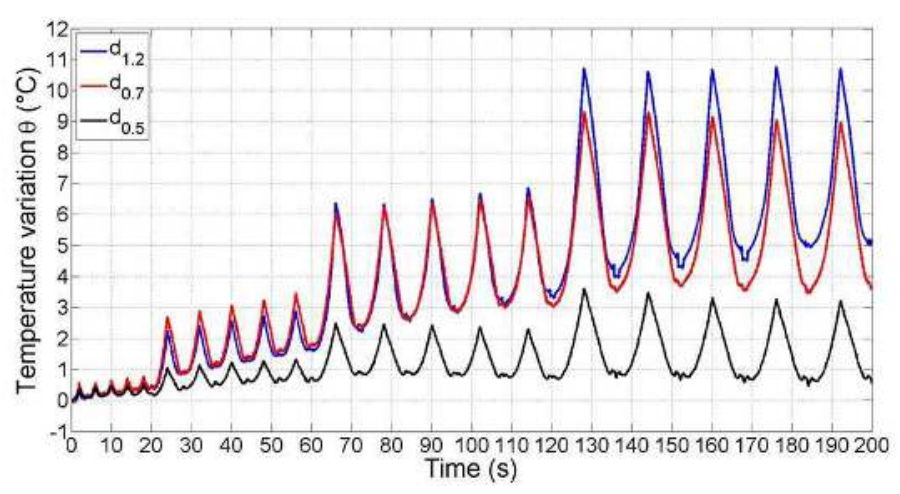

(b)

Fig. 10. Thermal response of the three densities (a) $\pm 100 \mathrm{~mm} / \mathrm{min}$ (b) \pm 300 $\mathrm{mm} / \mathrm{min}$

Even though the mechanical response is almost stabilized at the $2^{\text {nd }}$ cycle, the thermal response is not, far from it, especially in specimen $d_{1.2}$ for which the amplitude and the mean value of the temperature variation are stabilized 
at the $5^{\text {th }}$ cycle. Let us now detail more precisely the various contribution to the thermal response. The amplitude level of the thermal response is due to the thermomechanical couplings, the most important one being the entropic coupling, the loading rate, and the heat diffusion (mechanical characterization tests are generally carried out under non-adiabatic conditions). It should be noted that the amplitude can decrease if softening occurs. The stabilized mean value is due to the heat exchanged with the exterior of the specimen and heat produced by the viscosity and damage (intrinsic dissipation) leading to self-heating. In non viscous elastomers, the stabilized temperature variation oscillates around a value slightly superior to zero (see [29] for further information). This is observed for the lowest density at the lowest loading rate (see Fig 10(a)). When intrinsic dissipation occurs, the mean temperature variation increases from one cycle to another until equilibrium with heat diffusion is reached (see for instance Fig. 12(b)).

\subsubsection{Effect of the density}

As shown in Fig. 10(a) and 10(b), the higher the density, the higher the temperature variation amplitude and the higher the self-heating; the effects of the entropic coupling and the intrinsic dissipation increases. For a loading rate equal to $\pm 100 \mathrm{~mm} / \mathrm{min}$, the maximum difference in the minimum temperature variation between specimens $d_{1.2}$ and $d_{0.5}$ is $2.5^{\circ}$. For a loading rate equal to $\pm 300 \mathrm{~mm} / \mathrm{min}$, the difference is $4^{\circ}$. These values strongly depend on the non-adiabatic conditions and are therefore relative. Even though this result is logical, the fact that the difference between specimens $d_{0.5}$ and $d_{0.7}$ is much higher than between specimens $d_{0.7}$ and $d_{1.2}$ is not intuitable. Specimen $d_{0.5}$ exhibits a low temperature variation amplitude and a low self-heating 
level compared to the specimens of highest densities. This highlights therefore a density threshold effect in the self-heating. This result is of importance, since the design of TPU foam parts requires to find a tread-off between stiffness, energy absorption capacity and self-heating. To finish, the boxed zone in Fig. 10(a) presents the thermoelastic inversion, which is a phenomenon discussed below.

\subsubsection{Effect of the loading rate}

Comparing Fig. 10(a) and 10(b) shows that increasing the loading rate increases the self-heating effect (the intrinsic dissipation). Conclusions drawn for the effect of the density are not changed by increasing the loading rate, except that at the highest loading rate, the thermal responses of specimens of highest densities $\left(d_{0.7}\right.$ and $\left.d_{1.2}\right)$ are closer. This is the reason why, in the following, the discussion on characteristic effects in the thermal response is carried out only with specimens $d_{0.5}$ and $d_{1.2}$. It should be noted that the amplitude does not vary significantly while the loading rate is increased by a factor 3. This demonstrates that entropic effects are strongly weighted by energetic effects (change in the internal energy variations). This is in good agreement with the results reported in [30] for a compact PU. In this study, authors state that this effect is due to changes in the microstructure. Our conclusion is therefore that thermomechanical response of TPU in the compact as well as in the foamed states can therefore not be modeled efficiently without taking into account strong variations in the internal energy. 


\subsection{Characteristic phenomena detected in the thermal response}

Figures 11(a to d) and 12(a to d) give the temperature variations in relation to the stretch for specimens $d_{1.2}$ and $d_{0.5}$ at $\pm 300 \mathrm{~mm} / \mathrm{min}$.

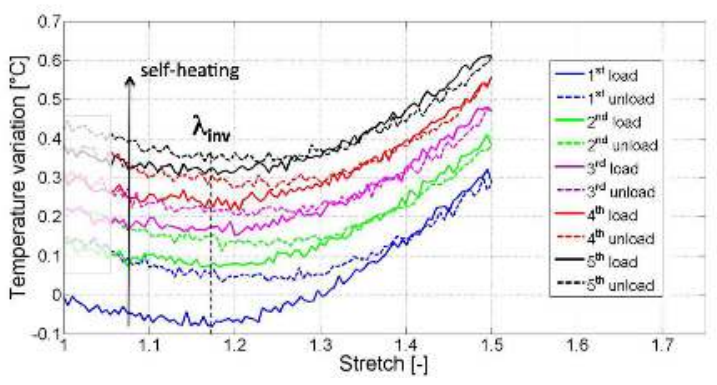

(a)

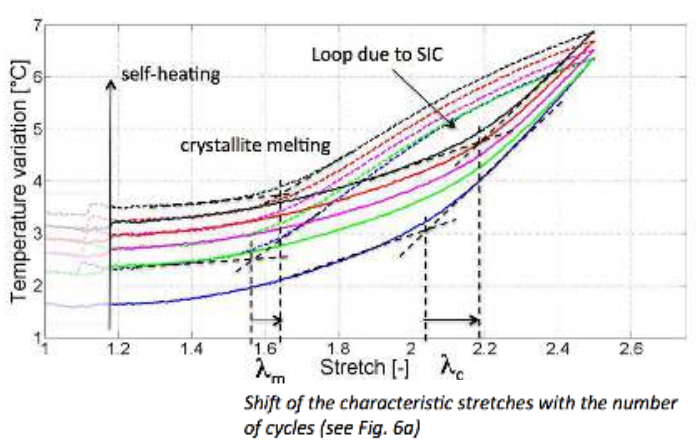

(c)

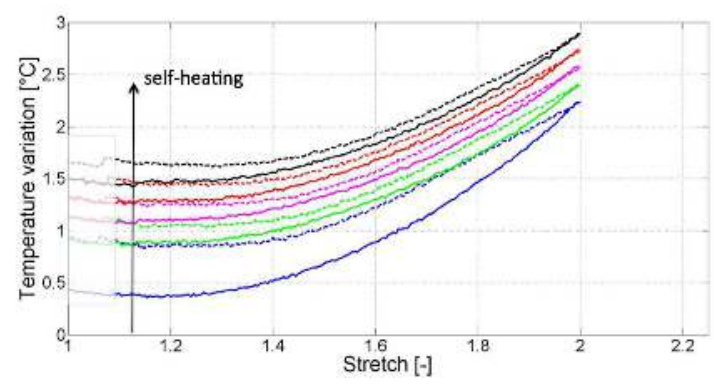

(b)

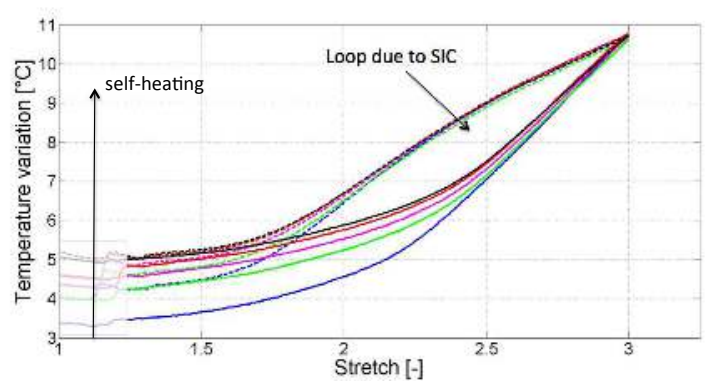

(d)

Fig. 11. Thermal response of specimen $d_{1.2}$ at $\pm 300 \mathrm{~mm} / \min$ (a) $\lambda_{1}=1.5$ (b) $\lambda_{2}=2(\mathrm{c}) \lambda_{3}=2.5(\mathrm{~d}) \lambda_{4}=3$

In these figures, the boxed zone is for the part of the test that must not be considered in the analysis. It corresponds to significant out-of-plane displacements due specimen buckling for negative stresses. In this case, the distance between the IR camera and the surface observed strongly changes and the temperature measurement is not valid anymore. The box is larger for the lowest density, which is consistent with the fact that the lowest density exhibits 


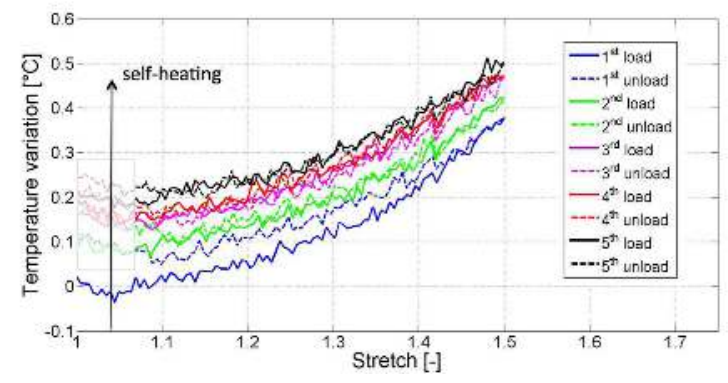

(a)

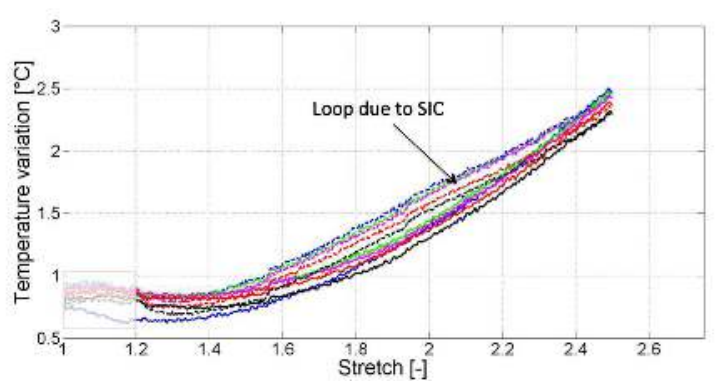

(c)

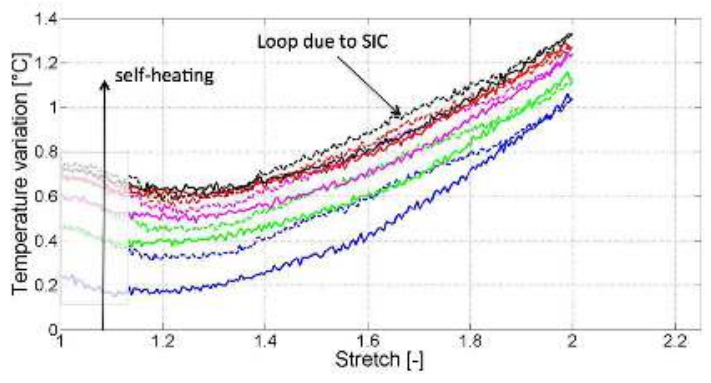

(b)

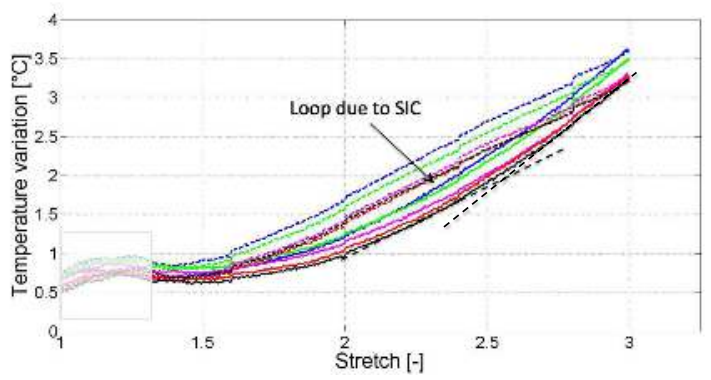

(d)

Fig. 12. Thermal response of specimen $d_{0.5}$ at $\pm 300 \mathrm{~mm} / \mathrm{min}$ (a) $\lambda_{1}=1.5$ (b) $\lambda_{2}=2$ (c) $\lambda_{3}=2.5$ (d) $\lambda_{4}=3$

the largest residual strain.

\subsection{1 thermoelastic inversion}

The thermal response of compact and foamed TPU exhibits a classical thermal effect observed in rubber $[31,32,20]$. Indeed, the thermal response is characterized by a slight cooling during stretching in the very low strain range, followed by a strong heating. Such thermo-sensitivity, induced by the competition between the effects of internal energy variation and entropy variation is referred to as the Gough-Joule effect $[33,31]$ in rubber materials. It should be noted that once specimen buckling occurs (corresponding to the boxed zones 
in the figures), out-of-plane displacements make the thermal measurement no longer valid, and the stretch at thermoelastic inversion, denoted $\lambda_{i n v}$ (see Fig. 11(a)), is therefore more difficult to determine. For the two specimens, the stretch at which the thermoelastic inversion is observed depends on the maximum stretch applied, and therefore the residual strain, during the previous cycle. This explains why for specimen $d_{0.5}$, which exhibits a larger residual strain than specimen $d_{1.2}$, the shift in the thermoelastic stretch is higher: the stretch at which the thermoelastic inversion occurs is between 1.15 and 1.2 for specimen $d_{1.2}$, while it is between 1.1 and 1.5 for specimen $d_{0.5}$.

\subsubsection{Strain-induced crystallization (SIC)}

When SIC starts, an additional heat is produced and a strong change in the thermal curve slope is observed at a stretch denoted $\lambda_{c}$. A change in the slope is also observed at a stretch denoted $\lambda_{m}$ when crystallites melt during unloading. $\lambda_{m}$ is inferior to $\lambda_{c}$, which is the signature of the supercooling effect (see [36]). A loop forms in the thermal response due to higher temperature variation during loading than during unloading. This is explained by the fact that crystallization continues during the unloading. This is illustrated in Fig. 11(c). As the test is not adiabatic, the value of the characteristic stretches $\left(\lambda_{c}\right.$ and $\left.\lambda_{m}\right)$ should be slightly lower. Moreover, the higher the maximum stretch reached and the number of cycles performed at the same maximum stretch (that increases the softening and the residual strain), the higher the value of the characteristic stretches. When the material is foamed, the temperature variations are lower, the self-heating is less, and the loops form due to SIC are smallest. Thus, identifying characteristic stretches is difficult. Nevertheless, an important result is that the loop area is lower than for the compact TPU. This 
seems to indicate that the crystallinity reached is lower. Such investigations on the effect of the density on SIC was possible because the TPU used in the compact and foams states was the same and this is an of the main contribution of the present study. SIC has already been observed in the thermal response of materials such as unfilled natural rubber [21], but to our knowledge such measurements have never been carried out in TPU, even less in relation to the density.

\section{Conclusion}

The present study investigates the thermomechanical behavior of TPU foams. Different densities were tested, including the compact state, which ensures a relevant characterization of the effect of the void volume fraction on the TPU's formulation used. A series of cyclic uniaxial tensile tests were carried out at different loading rates and different specimen densities. The softening was found to be only dependent on the maximum stretch applied. Contrarily, the residual strain and the hysteresis are clearly affected by changes in the loading rate and the density (the amount of viscous matter available). The thermal responses exhibit numerous particularities. First, the higher the density, the higher the temperature variation amplitude and the higher the self-heating, meaning that the effects of the entropic coupling and the intrinsic dissipation increases. Nevertheless, the change in the density has an effect on the thermal response only for a density equal to $0.5 \mathrm{~kg} / \mathrm{dm}^{3}$, which points out a density threshold effect in the self-heating. This result is of importance, since the design of TPUs foam parts requires to find a tread-off between stiffness, energy absorption capacity and self-heating. Second, when the loading rate is 
increased (by a factor 3), the temperature variation amplitude remains quite the same, which indicates that entropic effects are strongly weighted by energetic effects (change in the internal energy variations) in the material. This is in good agreement with measurements recently performed in a compact PU in [30]. Moreover, thermal measurements have highlighted that SIC and crystallite melting occur during the deformation. Their characteristic stretches evolve with the maximum stretch applied (increasing the residual stretch) and the number of cycles (inducing softening). Decreasing the density decreases the crystallinity reached. Finally, thermoelastic inversion has been characterized and discussed according to the density and the loading conditions. To conclude, this study provides information of importance on the specificities of the thermomechanical behavior of TPU, especially for modeling: the threshold effects of the density on the self-heating, the significant change in the internal entropy accompanying the deformation, the singularities in the cyclic thermal response due to SIC.

\section{Acknowledgements}

The authors thank the Cooper Standard France company for supporting this work and for fruitful discussions. The authors thank also the National Center for Scientific Research (MRCT-CNRS and MI-CNRS) and Rennes Metropole for supporting this work financially. SEM images were performed at CMEBA facility (ScanMAT, University of Rennes 1) which received a financial support from the European Union (CPER-FEDER 2007-2014). 


\section{References}

[1] L. Mullins, Effect of stretching on the properties of rubber. Rubber Chem. Technol. 21 (1948) 281-300.

[2] D. Blundell, G. Eeckhaut, W. Fuller, A. Mahendrasingam, C. Martin, Real time SAXS/stress-strain studies of thermoplastic polyurethanes at large strains. Polymer 43 (2002) 5197-5207.

[3] F. Yeh, B. Hsiao, B. Sauer, S. Michael, H. Siesler, In-situ studies of structure development during deformation of a segmented poly(urethane-urea) elastomer. Macromolecules 36 (2003) 1940-1954.

[4] E. Unsal, B. Yalcin, I. Yilgor, E. Yilgor, M. Cakmak, Real time mechano-optical study on deformation behavior of ptmo/chdi-based polyetherurethanes under uniaxial extension. Polymer 50 (2009) 4644-4655.

[5] L. Bartolome, J. Aurrekoetxea, M. A. Urchegui, W. Tato, The influences of deformation state and experimental conditions on inelastic behaviour of an extruded thermoplastic polyurethane elastomer. Mater. Des. 49 (2013) 974-980.

[6] H. Qi, M. Boyce, Stress-strain behavior of thermoplastic polyurethanes. Mech. Mat. 37 (2005) 817-839.

[7] P. J. Blatz, W. L. Ko, Application of Finite Elastic Theory to the Deformation of Rubbery Materials. Trans. Soc. Rheol. 6 (1962) 223-252.

[8] W. H. El-Ratal, P. K. Mallick, Elastic Response of Flexible Polyurethane Foams in Uniaxial Tension. J. Eng. Mater. Technol. 118 (1996) 157-161.

[9] M. Saha, H. Mahfuz, U. Chakravarty, M. Uddin, M. E. Kabir, S. Jeelani, Effect of density, microstructure, and strain rate on compression behavior of polymeric foams. Mater. Sci. Eng., A 406 (2005) 328-336.

[10] F. Saint-Michel, L. Chazeau, J.-Y. Cavaillé, E. Chabert, Mechanical prop- 
erties of high density polyurethane foams: I. Effect of the density. Compos. Sci. Technol. 66 (2006) 2700-2708.

[11] M. F. Alzoubi, E. Y. Tanbour, R. Al-Waked, Compression and Hysteresis Curves of Nonlinear Polyurethane Foams Under Different Densities, Strain Rates and Different Environmental Conditions. (2011) in: ASME 2011 International Mechanical Engineering Congress and Exposition Volume 9: Transportation Systems; Safety Engineering, Risk Analysis and Reliability Methods; Applied Stochastic Optimization, Uncertainty and Probability. Denver, Colorado, USA, November $11 ? 17$ (2011) 101-109.

[12] L. Ugarte, A. Saralegi, R. Fernandez, L. Martin, M. A. Corcuera, A. Eceiza, Flexible polyurethane foams based on $100 \%$ renewably sourced polyols. Ind. Crops Prod. 62 (2014) 545-551.

[13] A. Primel, J. Férec, G. Ausias, Y. Tirel, J.-M. Veillé, Y. Grohens, Solubility and interfacial tension of thermoplastic polyurethane melt in supercritical carbon dioxide and nitrogen A. J. of Supercritical Fluids 122 (2017) $52-57$.

[14] J.E. Martini-Vvedensky, N.P. Suh, F.A. Waldman, US Patent 4473665: Microcellular closed cell foams and their method of manufacture (September 1984).

[15] JS Colton, NP Suh, US Patent 5160674: Microcellular foams of semicrystaline polymeric materials (November 1992).

[16] L. Bartolome, A. Aginagalde, A. B. Martinez, M. A. Urchegui, W. Tato, Experimental characterization and modelling of large-strain viscoelastic behavior of a thermoplastic polyurethane elastomer. Rubber Chem. Technol. 86 (2013) 146-164.

[17] T. Rey, G. Chagnon, J.-B. Le Cam, D. Favier, Influence of the temperature on the mechanical behaviour of filled and unfilled silicone rubbers. 
Polym. Testing 32 (2013) 492-501.

[18] J. R. Samaca Martinez, J.-B. Le Cam, X. Balandraud, E. Toussaint,

J. Caillard, Filler effects on the thermomechanical response of stretched rubbers. Polym. Testing 32 (2013) 835-841.

[19] C. Prisacariu, Polyurethane Elastomers: from morphology to mechanical aspects, ISBN 978-3-7091-0513-9. (2011) Springer-Verlag, Wien.

[20] T. Pottier, M.-P. Moutrille, J.-B. Le Cam, X. Balandraud, M. Gré^diac, Study on the use of motion compensation technique to determine heat sources. application to large deformations on cracked rubber specimens. Exp. Mech. 49 (2009) 561-574.

[21] J. R. Samaca Martinez, J.-B. Le Cam, X. Balandraud, E. Toussaint, J. Caillard, Thermal and calorimetric effects accompanying the deformation of natural rubber. part 1: Thermal characterization. Polymer 54 (2013) $2717-2726$.

[22] B. Grady, S. Cooper, Thermoplastic elastomers. (2005) In: Mark JE, Erman B, Eirich FR, editors. The science and technology of rubber., San Diego: Elsevier Inc.

[23] H. Bouasse, Z. Carrière, Courbes de traction du caoutchouc vulcanisé. Annales de la Faculté des Sciences de Toulouse 5 (1903) 257-283.

[24] M. F. Beatty, S. Krishnaswamy, A theory of stress-softening in incompressible isotropic materials. J. Mech. Phys. Solids 48 (2000) 1931-1965.

[25] G. Chagnon, E. Verron, L. Gornet, G. Marckmann, P. Charrier, On the relevance of continuum damage mechanics as applied to the Mullins effect: theory, experiments and numerical implementation. J. Mech. Phys. Solids 52 (2004) 1627-1650.

[26] A. DeSimone, J. J. Marigo, L. Teresi, A damage mechanics approach to stress softening and its application to rubber. Eur. J. Mech. A/Solids 20 
(2001) 873-892.

[27] J. Diani, M. Brieu, P. Gilormini, Observation and modeling of the anisotropic visco-hyperelastic behavior of a rubberlike material. Int. J. Solids Struct. 43 (2006) 3044-3056.

[28] R. Diaz, J. Diani, P. Gilormini, Physical interpretation of the Mullins softening in a carbon-black filled SBR. Polymer 55 (2014) 4942-4947.

[29] X. Balandraud, J. B. Le Cam, Some specific features and consequences of the thermal response of rubber under cyclic mechanical loading. Arch. Appl. Mech. 84 (2014) 773-788.

[30] P. Mott, C. Giller, D. Fragiadakis, D. Rosenberg, C. Roland, Deformation of polyurea: Where does the energy go? Polymer 105 (2016) 227-233.

[31] J. P. Joule, On some thermodynamic properties of solids. Phil Mag 4th $14(1857) 227$.

[32] R. L. Anthony, R. H. Caston, E. Guth, Equations of state for naturals and synthetic rubber like materials: unaccelerated natural soft rubber. J. Phys. Chem. 46 (1942) 826.

[33] J. Gough, A description of a property of caoutchouc or Indian rubber; with some reflections on the cause of the elasticity of this substance. Mem. Lit. Phil. Soc. Manchester 1 (2nd Series) (1805) 288-295.

[34] G. Machado, G. Chagnon, D. Favier, Analysis of the isotropic models of the mullins effect based on filled silicone rubber experimental results. Mech. Mater. 42 (2010) 841-851.

[35] M.S. Loo, J.-B. Le Cam, A. Andriyana, E. Robin, Inelastic responses of swollen nitrile rubber under cyclic loading. To appear in Rubber Chem. technol. (2017).

[36] S. Trabelsi, P.-A. Albouy, J. Rault, Crystallization and melting processes in vulcanized stretched natural rubber. Macromolecules 36 (2003) 7624-7639. 